\title{
2
}

\section{REVITALISASI KEARIFAN LOKAL SUNDA}

Jakob Sumardjo

\begin{abstract}
In Sundanese culture, local wisdom is the middle sineger (sineger tengah) or middle siger (siger tengah) a middle ground that is moderate. The excavation of local Sundanese wisdom means finding a rational pattern or basic philosophy that is suitable for living in this area. In other areas where the situation is similar it is possible to find a basic philosophy which is more or less the same. Foreign local wisdom which enters the local wisdom of Sundanese tends to conform not the other way around. Times will always change but Sundanese become another Sundanese of its own kinds. The outward form can change, but the structure and pattern of building the meaning of life tend to remain work genetically unnoticed because since childhood has been investigated by the older generation in the same pattern. The revitalization of Sundanese culture is necessary or not depending on its actuality to solve the present problems.
\end{abstract}

Keywords: revitalization, local wisdom, meta-duality

\section{PENDAHULUAN}

Inti kearifan lokal Sunda adalah sineger tengah atau siger tengah,_dalam Bahasa Indonesia dapat diterjemahkan dengan jalan tengah. Pemikiran moderat memperlakukan segala sifat atau kualitas segala sesuatu yang saling mengeksistensi, saling melengkapi, dan saling menyempurnakan. Kesempurnaan adalah mengharmonikan segala sesuatu yang bersifat kontradiktif dalam suatu entitas (keberadaan) baru yang mengandung sifat-sifat saling bertentangan, dengan sendirinya bersifat paradoks. Paradoks dalam arti positif yakni saling melengkapi kekurangan masing-masing oleh kelebihan masing-masing yang membuat pasangan itu tampak kontradiktif.

Hanya ada dua kemungkinan pemecahan dari kedua keberadaan yang saling melawan sifatnya, yakni saling meniadakan atau saling menghidupkan. Saling meniadakan membiarkan potensi konflik pasangan kontradiktif tadi menjadi ajang adu kekuatan yang saling menghancurkan sampai terjadi lenyapnya salah satu entitas. Hasil akhir jalan kekerasan (ekstrim) ini adalah peniadaan kedua-duanya atau kemenangan salah satu, yang berarti keberadaan tanpa pasangan kontradiksinya. Seperti disebutkan di atas, semua yang ada di alam semesta ini merupakan pasangan sifat atau karakter yang saling meng-ada-kan sifat-sifat tersebut. Kalau salau satu sifat dilenyapkan, misalnya "panas", maka yang disebut "dingin" (kontradiksinya) tidak akan ada.

Untuk memelihara tetap adanya sifat-sifat dalam hidup ini, maka perlu ditempuh cara moderat, yakni jalan tengah atau sineger tengah. Sineger tengah menyingkirkan potensi konflik dari dua entitas yang saling bertentangan sifatnya dan memilih potensi saling melengkapi dan saling menyempurnakan. Hidup ini tidak 
sempurna karena masing-masing yang ada ini terbatas sifat-sifatnya. Keterbatasan menimbulkan perbedaan. Perbedaan menimbulkan konflik kalau ada dua entitas saling berlawanan sifatnya. Potensi konflik kalau dibiarkan akan menimbulkan kematian salah satu atau kedua-duanya,yang berarti hidub ini tidak mengandung potensi kehidupan. Bagaimana mengubah potensi konflik itu menjadi potensi kehidupan? Tak ada jalan lain kecuali menciptakan atau membentuk entitas ketiga yang mengandung harmoni saling melengkapi dan saling membenarkan antar dualitas yang kontradiktif tersebut. Entitas ketiga inilah jalan tengah atau seneger tengahnya.

Pembentukan jalan tengah yang paradoksal ini menuntut kerja budaya tingkat tinggi. Tidak mudah mendamaikan dua entitas yang saling bertentangan sifatnya menjadi saling memberi dan saling menerima sifat masingmasing. Untuk itu diperlukan kreativitas, kecerdasan, dan kearifan khusus yang istimewa.

Sineger tengah adalah jalan perdamaian, harmoni, terbuka, toleran, saling membenarkan, menyadari kodrat perbedaan, hidup saling mengasihi (silih asih), saling mengingatkan (silih asah), dan saling melindungi atau memelihara perbedaan masing-masing (silih asuh). Perbedaan itu sudah kodrat yang diterima manusia sejak awalnya. Manusia memiliki potensi berpikir yang dapat mencari jalan bagaimana hidup ini dapat terus dipelihara dengan meredam potensi konflik yang kodrati itu. Inilah cara kebudayaan, suatu kesadaran kolektif suatu masyarakat yang dijadikan pegangan untuk hidup bersamaan secara damai, harmonis, menuju kesejahteraan hidup di dunia ini.

Konsep dasar sineger tengah ini digali asal usulnya dari serpihan-serpihan data yang kini tersebar di Jawa Barat ini. Dengan data-data terbatas inilah akan ditunjukan konsep dasar sineger tengah ini dari mitologi-mitologi tua, ungkapan verbal, benda-benda budaya tradisi etnik, dan lain-lain.

\section{Pasangan Pertentangan Keberadaan}

Keberadaan ini terdiri dari pasangan dualitas yang saling bersebrangan kualitas atau sifatnya, sudah ada dalam mitologi masyarakat Kanekes (Baduy) yang dicatat oleh Suria Saputra (Susra) dalam manuskripnya yang dibuat pada tahun 1950. Dalam Naskah 7 yang berjudul "Adat Lembaga" (Baduy), ia menulis sebagai berikut:

"Sepanjang kepercayaan orang-orang Tangtu (Baduy Dalam) sising ini sebelum turun ke dunia, datang dari sang Rama diterima oleh sang Ambu atau Sunan Ambu. Ambu ini disebut Ambu Langit bernama Ambu Si Sudakara. 'Lajuna' kata informan kami, 'Mun wasa jadi cacahan cara jalma, meureun kieu. Pagon ku $\underline{\text { Bapa geh baris dicecahkeun deui beda lapa }}$ tunggal manah' (seterusnya, kalau mungkin diceritakan sebagai manusia, barangkali begini. Tapi Bapak pun akan menceritakan lagi dengan kata-kata yang berlainan dalam isi yang sama). Ketika Aing menerima tugas dari Ambu Langit ini, seolah-olah menolak untuk turun ke Buana Pancatengah itu. Alasan penolakan, bahwasanya 
di Buana Pancatengah: seuneuna panas, beusina seukeut, usik malik wawangenan (apinya panas, besinya tajam, bergerak pun dibatasi). Maka berkatalah Ambu Langit: ' Turunlah anakku di Buana Tengah. Panas dapat didinginkan, tajam dapat ditumpulkan. Semua-mua (bahasa Baduy semuah-muah) di Pancatengah dapat dijadikan dunia. Anakku tak usah kawatir, segala-galanya telah disiapkan untuk anakku".

Tafsir: mengapa manusia dilahirkan di dunia ini? Manusia dilahirkan di dunia karena tugas dari Sang Rama (di Buana Nyungcung?). Tugas untuk mengenal dualitas sifat-sifat. Sebelum turun ke dunia (Buana Pancatengab) si Aing telah mengenal sifat-sifatnya, yaitu dari alasannya tak mau turun ke dunia, karena apinya panas, besinya tajam dan bergerak saja dibatasi (tidak merdeka). Dan tentu saja telah mengenal nilai atau sifat sebaliknya, yakni dingin, tumpul, tidak bebas (terikat aturan). Tetapi di alam asal tadi (Buana Nyungcung?) semua sifat atau nilaitadi masing-masing tunggal (mengesa) tanpa ada hubungan satu dengan yang lain. Di dunialah si Aing akan mengenal hubungan sebab-akibat antara panas dan dingin, tajam dan tumpul, serta bebas dan terikat. Kata orang Baduy: semuahmuah dapat dijadikan dunia, artinya kedua pasangan dualitas saling berlawanan sifatnya tadi harus diterima seperti apa adanya. Segala sesuatu di dunia ini, yang saling berlawanan nilainya, harus diterima sebagai kebenaran. Tidak boleh melenyapkan salah satu pasangan dualitas. Bagaimana memedamkan panas kalau tidak ada dingin, menghilangkan tajam kalau tidak ada pengertian tumpul? Atau sebaliknya, yakni hanya yang tumpul dapat ditajamkan, yang dingin dapat dipanaskan.

Pasangan kembar keberadaan ini, yang biasanya diidentikkan sebagai pasangan kualitas kelaki-lakian dan keperempuanan, di kampung adat sering disebut Sakuren (pasangan sejodoh). Keberadaan sakuren ini tidak boleh diubah kualitasnya sedikitpun. Pikukuh Baduy menyatakan:

\section{Gunung tak boleh digempur}

\section{Lembah tak boleh dirusak}

\section{Panjang tak boleh dipotong}

\section{Pendek tak boleh disambung}

Yang dilarang harus dilarang

Yang benar harus dibenarkan

Dalam masyarakat adat, yang sakuren tadi diharmoniskan dalam pancer pangawinan yang merupakan keberadaan baru sebagai sineger tengahnya.

Si Aing diturunkan ke dunia supaya mengenal hukum sebab-akibat (kausalitas keberadaan). Bagaimana sesuatu dinilai benar kalau tidak mengenal sesuatu yang salah? Untuk mempertahankan yang benar, maka yang salah tidak boleh dilenyapkan. Kalau yang salah itu dilenyapkan bagaimana yang benar tetap benar? Itulah sebabnya ada yang menyatakan bahwa kejahatan di dunia tak mungkin dilenyapkan, hanya dapat dikurangi, supaya kebenaran tetap bersinar.

Tafsir terhadap mitologi Baduy ini adalah bahwa manusia ditugaskan turun ke dunia supaya mengenal hukum kausalitas dunia, 
agar supaya kalau kembali ke asal, kebaikan lebih bermakna, kesucian dan kemuliaan lebih tinggi maknanya. Bagitu pula sebaliknya, mampu menempatkan kejahatan pada tempatnya. Di dunia segalanya serba sementara, terbatas dan rentan perubahan. Kamarau (panas, api) dapat lebih panjang dari penghujan (dingin, air) atau sebaliknya, sehingga diperlukan keseimbangan agar nilai keduanya tidak lenyap. Perubahan dapat membuat dualitas tidak seimbang dan mengancam musnahnya salah satu pasangan entitasnya.

\section{Meta-Dualitas}

Dualitas atau pasangan kembar oposisioner yang saling meng-Ada-kan telah hadir sejak awal keberadaan. Dualitas primordial ini berupa Sunnng X Eusi atau Kosong dan Isi atau Teu Aya dan Aya. Di Jawa entitas Teu Aya ini disebut Sang Hyang Matoyo. Sumber utama yang menjelaskan konsep ini ada dalam cerita pantun Panggung Karaton oleh juru pantung Ki Aceng Tamadipura dari Situ Raja, hasil rekaman Ajip Rosidi tahun 1971.

Dalam cerita pantun ini terdapat sebuah "siloka" yang disayembaran untuk dibedah isi teka-tekinya oleh para pelamar puteri Bungsu Rarang, adik raja lokal PanggungKaraton di kerajaan Dayeuh Panggung. Siloka itu oleh juru pantun disebut sebagai "ilmu kosong Galuh". Puisi teka-teki itu lengkapnya sebagai berikut:

\section{Teras kangkung galeuh bitung}

\section{Tapak meri dina leuwi}

Tapak soang dina bantar
Tapak sireum dina batu

Kalakay pare jumarum

Sisir serit tanduk ucing

\section{Sisir badag tanduk kuda}

Kekemben layung kasunten

Karumbuah kuwung-kuwung

Tulis langit gurat mega

Panjangnya sabudeur jagat

Inten segede baligo

Terjemahan:

Inti batang kangkung inti bambu betung

Jejak itik di air

Jejak angsa di tanah bantar

Jejak semut di batu

Batang padi kering meruncing

Sisir rapat tanduk kucing

Sisir besar tanduk kuda

Berkemben langit senja

Pelangi di angkasa raya

Tulisan di langit gambar di mega

Panjangnya sebulat dunia

Intan sebesar buah baligo

Tafsir singkat pusisi ini dimulai dengan adanya dua bait puisi yang masing -masing terdiri dari 6 baris, setiap baris berisi 8 patah kata. Jumlah 6 dan 8 itu ada artinya, tetapi tidak dibahas sekarang.

Bait pertama dimulai dengan makna "kosong dalam kosong", yaitu inti batang kangkung yang kosong isinya adalah kekosongan inti batang bambu betung yang justru lebih besar 
kosongnya. Ini menunjukan ada keberadaan Kosong yang tak terbatas yang berada dalam kekosongan terbesar yang dikenal manusia.

Selanjutnya disebutkan adanya jejak itik yang berenang di permukaan air, jejak angsa di bantaran, dan jejak semut di batu, yang seharusnya ada kenyataan kosong, tak ada. Semua yang nampak ada bagi manusia ternyata kekosongan belaka. Aya teh euweh. Lalu disebutkan batang padi kering yang runcing sebagai jarum, menggambarkan sesuatu yang panjang tegak kaku, itulah simbol maskulinitas, sifat kelaki-lakian. Akhir bait ini menyebutkan sisir serit (sisir suri) yang biasa untuk mencari kutu kepala, itulah menggambarkan dunia manusia yang penuh penyakit ini.

Bait kedua adalah pasangan terbalik dari bait pertama, karena dimuali dengan bagian akhir bait pertama. Dengan demikian baris pertama bait pertama justru berpasangan dengan baris terahir bait kedua. Dua bait puisi ini dipasang secara berbalikan, yang merupakan pasangan oposisioner (berbalikan), yang oleh masyarakat adat Kasepuhan Banten Kidul disebut dua sakarupa. Hal ini akan dijelaskansi belakang.

$$
\text { Bait kedua dimulai dengan }
$$
menggambarkan sisir badag (besar dan jarang) sebagai tanduk kuda. Binatang kuda sering dipakai untuk nama para kesatria cerita pantun yang terhormat, simbolmanusia yang sempurna, misalnya Kuda Wangi dan Kuda Gandar, kuda berbalikan dengan kucing. Kalau kucing simbol dunia manusia, maka kuda simbol langit, dunia rohaniah. Mengapa tanduknya berupa sisir besar? Sisir ini digunakan untuk berdandan, yakni merapikan rambut kepala, yang berarti lambang keteraturan atau sebuah kosmos. Dunia manusia adalah Chaos.

Selanjutnya digambarkan adanya pelangi di langit senja, langit yang penuh tulisan (ajaran) dan mega yang bergambar, yang semuanya itu di langit yang feminimitas (kekemben). Langit diatas yang "kosong" justru penuh sesak dengan eusi. Isi langit itu sepenuh-penuhnya isi dan sepadatpadatnya isi. Ibarat intan sebesar buah baligo (jenis semangka). Intan tidak berwarna (bening) tapi mengandung semua warna.

Siloka teras kangkung ini menjelaskan dasar dualitas yang metafisik. Dalam tuturan rakyat sering dikatakan:

\section{Ayana aya}

\section{Ayana euweuh}

\section{Euweuh teh aya}

\section{Aya teh euweuh}

Itulah makna siloka istimewa tersebut. Yang disebut Aya (bait kedua) adalah daya hidup, energi, kekuatan, tenaga, gerak, yang membuat hidup ini mungkin. Semua itu nampak, tak terindra, kosong, suwung, euweuh, namun semua yang hidup nampak ini berasal dari padanya. Disebut ada karena adanyaTidakada. Disebut Tidak-ada karena adanya Ada. Inilah prinsip pertama dualitas segala sesuatu.

\section{Penghubung Kosong dan Isi}

Bagaimana kosong (suwnng, euneuh, teu aya/mataya, awang uwungan) yang sebenarnya 
justru isi yang seisi-isinya (daya hidup, energi) hadir di dunia manusia (isi yang kosong), agar supaya kehidupan ini terus berlangsung secara baik dan sempurna? Selamat? Menurut manuskrip Baduy Suria Saputra dikisahkan bahwa sebelum semua ini ada, yang ada terlebih dahulu adalah Suwnng awang-awang uwnng-unungan (Kekosongan mutlak). Dari kesuwungan itu muncul keluar 3 Batara, yakni Batara Mahakarsa, Batara Mahakawase, dan Batara Bima Mahakarana. Tiga Batara itu kemudian menyatu menjadi Batara Tunggal (Batara Esa). "Batara Tunggal itu menciptakan alam, yang menjadi sebab adanya alam, mengatasi segala keadaan. Sedang menurut Baduy, Batara Tunggal itu merupakan kesatuan dari tiga Batara sebagaimana diterangkan di atas", tulis Susra.

Menurut Susra, orang Baduy itu monotheis, mengakui adanya Tuhan Yang Maha Esa. Tuhan tersebut terstruktur dari tiga potensi dasar kehidupan, yaitu kersa atau kehendak atau tekad, kawarsa atau tenaga, energi atau lampah, dan karana sepadan dengan kata "karena" yang berarti pemikiran atau ucap. Mengapa ucap sama dengan pikiran, karena pikiran hanya dapat dilakukan dan dinyatakan dalam bahasa, dalam kata-kata.

Bahwa Batara Tunggal atau Yang Esa tadi adalah Sang Hyang Hidup itu sendiri, dapat disimak dari naskah Sunda lama, yakni Sawaka darma.
Kari raga tanpa mudele

Leuwih tan keutaman

Lamun anggeus ditinggalkeun

Ku na Bayu Sabda Hedap

Aing ku Sang Hyang Hurip

Terjemahan:

Kalau tak ada yang diundang

Kalau tak ada dalng

Panggung tinggal sunyi sepi

Tinggal raga tanpa jiwa

Lebih tak berarti lagi

Kalau ditinggalkan Lampah Ucap Tekad

Aku ditinggalkan oleh Sang Hyang Hidup

Batara Tunggal adalan Lampah-UcapTekad adalah Sang Hyang Hurip itu sendiri. Tanda sesuati itu hidup karena ada gerak padanya. Gerak hanya mungkin kalau ada tenaga atau energi. Tetapi sesuatu yang belum tentu "Hidup" Itu sendiri kalau tidak didahului oleh adanya (Batara Maha Karana) adan adanya tekad-kehendak-keinginan (Batara Kersa).

Dari data-data diatas, kiranya jelas ketiga Batara Lampah-Ucap-Tekad, merupakan Sineger tengah atau Siger tengah antara suwung/kosong dengan Batara Tunggal atau Yang Esa. Kalau digambarkan sebagai berikut:

\section{Lamun beutung nu ngundang}

Lamun hanteu nu nyarita

Panggung lagi datang meneng 


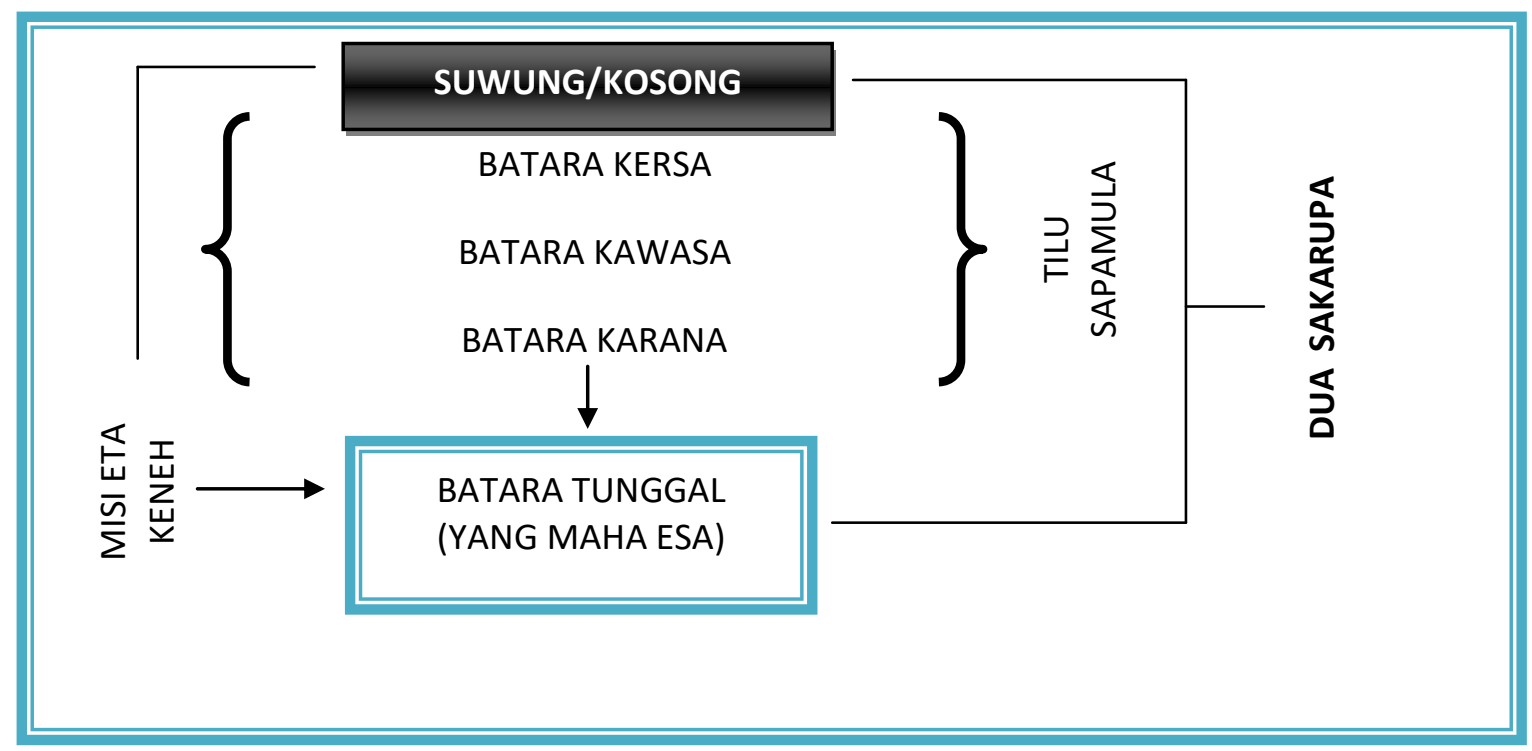

Gambar 1

Gambaran Tiga Batara

Sineger tengah itu mengandung dualitas esensial, dalam hal ini Kosong adalah Isi, sehingga Suwung atau Kosong tak lain adalah Batara Tunggal dan Batara Tunggal tak lain adalah Suwung itu sendiri. Dalam hal dapat ditafsirkan bahwa Suwung adalah kondisi nonmanifest, non-aktual, dan dengan sendirinya noneksisten (Tak ada). Sedangkan Batara Tunggal adalah manifestasi, aktualisasi, dan dengan mediasi Suwung dan Isi adalah 3 Batara KersaKawasa-Karana atau tekad-lampah-ucap, yang dalam kitab Sunda Lama, Siksa Kanda ng Karesian (1518) dinamai Tri Tangtu.

Dalam masyarakat adat kasepuhan Banten Kidul dikenal ungkapan sebagai berikut:

\section{Tilu sapamulu (a)}

\section{Dua sakarupa}

\section{Hiji eta keneh}

Ungkapan ini mungkin tidak disadari dapat diterapkan pada konsep Tritangtu metafisika ini.
Pada awalnya muncul Tiga batara (tilu sapamula). Yang tiga Batara ini menyatu menjadi Batara Tunggal, sehingga muncul dua sakarupa, yang tak lain Suwung adalah Yang Esa, Yang Esa tak lain adalah Suwung. Keseluruhanya itu tak lain adalah Hiji Eta Keneh, yakni Yang Maha Esa itu.

Bagi manusia modern apa yang disebut "Kosong" atau Suwung atau tiada itu tak punya makna karena memang tak ada. Namun pakar psikologi Carl Gustaf Jung, dalam tulisanya, "Tujuh Kotbah Untuk Orang-Orang Mati" (1916) antara lain menyatakan: "Dengarkan: saya mulai dengan kekosongan, kehampaan. Kekosongan sama dengan kepenuhan. Dalam infinitas, penuh tidak lebih dari kosong. Kekosongan adalah dua hal tersebut, penuh dan kosong. Sesuatu yang tidak terbatas dan abadi tak membawa sifat, karena ia memiliki semua sifat".

Dualitas sifat yang dikenal manusia (dan Aing di Buana Nyungcung), tidak mungkin 
memasuki Suwung. Kita menyebutnya Suwung dari pengalaman duualitas manusia saja, hanya ibarat kata Jung. Pikiran kita: dualitas dalam Suwung begitu penuh dan sempurnanya sehingga dapat saling "meniadakan" sifat-sifat, sehingga "tidak bersifat" justru penuh padat dengan semua sifat yang kita kenal maupun tak mungkin kita kenal.

Sunving baru dekenal manusia setelah ada manifestasi dan aktualisasi yang keluar menyembul dari ketiadaan itu. Dengan demikian mitologi Baduy yang dicatat Suria Saputra tahun 1950-an langsung dari masyarakat waktu itu merupakan salah satu manifestasi dan aktualisasi Suwung.

\section{Si Ijunajati wistemen}

Dalam kitab Jatiraga yang dituliskan dalam aksara Sunda lama dan bahasa Sunda lam (Kropak 422) disebutkan bahwa dalam Sunung (uwnng-uwung manuruwung) ada sosok penghuninya yang disebut Si Ijunajati. Sosok ini, seperti Suwung. Tidak dapat dikenal manusia. Ia mengenalkan dirinya (manifestasi dan aktualisasi) melalui dewa-dewa yang dikenal dalam kebudayaan Sunda zamanya, misalnya Sang Hyang Aci, Batara Niskala, Sang Hyang Permana dan lain-lain. Dewa-dewa itulah yang selalu berkata: Aing inya eta inya aing. (Aku adalah $\mathrm{Dia} / \mathrm{Itu}$ sebagai aku) lalu Ijunajati menyatakan siapa dirinya. Inilah antara lain yang dkatakan Si Ijunajati (Suwung) itu:

"Aku yang membuat aku pula yang dibuat.

Aku yang Ada. Aku pula yang Tiada.
Aku yang melihat. Aku pula yang dilihat. Aku yang melihat di luar kehidupan

Di luar kodrat

Di luar Yang Maha Melihat

Aku tak terkatakan, tak terasakan, tak terdengar, tak terlihat.

Sedangkan Aku sama sekali tak diketahui.

Sejak awal Aku tidak diketahui oleh manusia

Itulah sebabnya Aku keluar dari Ketiadaan

Dari situ pula perasaan jiwa Tekad, Lampah.

Ucap menyembul keluar meninggalkan kekosongan."

Yang menarik dari naskah ini adalah pernyataan Si Ijunajati "yang menyembul keluar dari Kekosongan dengan Tekad, Lampah, Ucap” yang sangat mirip dengan mitos Baduy yang dituturkan Suria Saputra. Tekad-LampahUcap, Tritangtu itu adalah sineger tengah antara Si Ijunajati8 dengan para dewa yang dikenal oleh masyarakat Sunda pada zamanya, seoerti halnya Batara Kersa/Tekad, Batara Kawasa/Lampah, dan Batara Karana/ Ucap merupakan sineger tengah dari Suwung awang-awang uwunguwungan Batara Tunggal yang dapat dihubungi manusia.

\section{Ngala Suwung}

Dalam masyarakat Kasepuhan Banten Kidul dikenal ungkapan "ngala suwung" atau mencari suwung agar semua yang dilakukan dan 
dihasilkan dalam hidup ini selamat, lestari dan aman sejahtera. Suwung bagi mereka diartikan sebagai tapak meri dina lewni, tapak soang di awangawang, sesuatu yang ada dalam tiada.

Salah satu jalan untuk menghadirkan Suwung adalah dengan tilu sapamilu, dua sakarupa, biji eta keneh,_atau dalam Siksa Kanda disebut tritangtu. Atau dalam filosofi yang kita bahas menemukan sineger tengah atau siger tengah dari pasangan dualitas.

Dalam menghadirkan suwung (ada yang tiada itu) dipertimbangkan bobot wadah dan eusi. Wadah adalah wujud nampak berupa tindakan, ucapan, atau benda-benda yang begitu rupa sehingga eusi (sumung) hadir di situ secara menetap atau temporer saja.

Dalam cerita pantun badak Pamalang oleh juru pantun Ki Samid dari Cisolok, Sukabuli, berulang-ulang dinyanyikan puisi ini:

\section{Mun kawih si bangbalikan mun cangkang reujeung eusina}

\section{Kudu sarua lobana}

\section{Bisi kawih mamarueun}

\section{Baribin bailiking kawih}

Neda agung dina paralun

Neda panjang nu hampura

Terjemahan:

Jika lagu dinyanyikan terbalik

Jika wadah dengan isinya

Harus sama besarnya
Kalau-kalau lagu mandua

$$
\begin{aligned}
& \text { Menyertai baliknya lagu } \\
& \text { Hamba mohon besarnya maaf } \\
& \text { Mohon panjang ampunannya }
\end{aligned}
$$

Lagu si bangbalikan telah kita lihat pada siloka Panggung Karaton. Bait pertama dari awal sampai akhir, bait kedua dari akhir kembali ke awal. Si bangbalikan tak lain adalah ucapan aing. Tepo sliro, manjing ajur ajer, aku melebur menjadi dirimu, dirimu melebur ke dalam aku. Guru menjadi murid, murid menjadi guru. Pemimpin melebur ke rakyat, rakyat memahami tugas pemimpin. Yang diatas ke bawah, yang bawah ke atas, murid guru, rakyat pemimpin. Sineger tengah. Jalan atau metode bagaimana Suwung, Tuhan Yang maha Esa hadir disitu. Sang Hyang Hurip hadir disitu. Itulah makna Ketuhanan Yang Maha Esa. Sifat-sifat Tuhan hadir di Sineger tengah.

Ngala Sumung ada di upacara adat, ada di nyanyian,di permainan anak-anak, ada di boboko, ada di kabuyutan, ada di bedog dan kujang, ada di rumah adat, dan banyak lagi. Disitu ada "tilu sapamulu,dua sakarupa, hiji Eta keneh". Itulah kearifan lokalnya apabila ditinjau secara filosofis. Masyarakat tiap hari melakukanya, tetapi tdak menyadari dasar filosofinya. Masyarakat hanya tahu bahwa wujud dan bentuk seperti itu baik benar adanya, agar hidup ini salamet. 


\section{Kesadaran Sineger Tengah}

Sebenarnya masyarakat adat memiliki ungkapan dasar yang menunjuk pada filosofi tilu sapamulu atau tritangtu ini. Suria Saputra mencatatnya dari kearifan orang Baduy begini bunyinya:

\section{Lulurung tilu ngabandung}

\section{Lalaran dua dikipas}

\section{Disaba di tengah-tengahna}

\section{Bisi jalan mamaruan}

\section{Nu notog ka padaleman}

Terjemahan:

Ada tiga lorong berjajar

Lekas tinggalkan yang dua

Tempuhlah lorong yang di tengah

Kalau-kalau jalan mendua

Yang menuntun ke pe-Dalem-an

Lorong tengah yang mamaruan, mendua, paradoks, itulah sineger tengah yang mengandung hiji Eta Keneh atau Tilu Sapamula atau Sang Hyang Hurip. Dan seperti sudah diungkapkan, lorong tengah yang mamaruan itu tak ada resepnya, tiap orang harus kreatif menemukan sineger tengahnya. Tritangtu adalah prinsip dasar atau filsafat dasar (metafisika) yang mencari gambaran sangat umum atas struktur segala sesuatu yang menjadi karakter bagi semua yang ada, akan ada, maupun yang dapat ada. Kalau metafisika kearifan lokal ini sudah difahami, maka tidak ada lagi tuduhan kearifan lokal itu zaman dulu yang sudah lewat. Filosofi kearifan lokal tetap aktual. Semua itu tergantung pada kita sendiri di masa kini, apakah kita lebih cerdas atau lebih bodoh dari nenek moyang kita yang sejak dahulu mempraktekkan metafisikan sineger tengah ini.

Bahwa mereka berhasil hidup tata tentram kerta raharja di kampung-kampung adat, betapa sehederhanyanya pun, karena mereka tanpa disadari atau bekerja secara intuitif kearifan lokal sineger tengah. Kini tantangan bagi kita, apakah dalam perubahan zaman ini kita cukup kreatif menterjemahkan filosofi Sineger Tengah masa kini.

Apa yang kita pelajari adalah hasil kreativitas nenek moyang masa lampau. Kita tidak akan kembali melakukan karya kreatif mereka pada zamanya, yang berarti menghidupkan mayat kebudayaan atau zombie. Kita harus membangun karya-karya kreatif berdasarkan filsafat dasaratau metafisikan nenek moyang itu, karena kita hidup di tempat yang sama seperti dialami nenek moyang.

\section{KESIMPULAN}

Menggali kearifan lokal berarti mencari pola rasional atau filosofi dasar yang cocok untuk hidup di daerah ini. Ada kemungkinan bahwa daerah-daerah lain yang situasinya mirip akan menemukan filosofi dasar yang kurang lebih sama. Daerah-daerah yang kondisi alamnya amat berbeda akan menemukan filosofi dasar yang berbeda. Itulah sebabnya kearifan lokal asing yang memasuki kearifan lokal setempat selalu ada kecenderungan menyesuaikan yang asing itu pada kearifan lokalnya sendiri, dan bukan sebaliknya. 
Perubahan adalah sesuatu keniscayaan. Perubahan itu kodrati. Kearifan lokal berubah. Tetapi apakah perubahan itu? Menurut Louis Katschopp, perubahan adalah sesuatu menjadi sesuatu yang lain dari sesuatu itu sendiri. Sunda menjadi Sunda yang lain dari kesundaannya sendiri. Apa yang disebut kesundaan tak lain adalah prinsip dasar atau filosofi dasar yang berupa struktur hubungan tetap yang berulangulang dipakai dalam memecahkan masalah zamanya. Bentuk luarnya dapat berubah, bahkan paling mudah berubah, namun struktur dan pola membangun makna hidupnya cenderung tetap, bekerja secara genetik tanpa disadari, karena sejak kecil telah disidik oleh generasi tuanya dalam pola yang sama.

Apakah revitalisasi kearifan lokal diperlukan masa kini? Tergantung pada kita apakah metafisika Sineger Tengah masih aktual untuk memecahkan masalah-masalah kekinian.

\section{DAFTAR PUSTAKA}

Undang, A. Darsa, dan Edi, S. Ekadjati, 2006. Gambaran Kosmologi Sunda. Bandung: Kreasi.

Suria Saputra (Sursa).

1950. Baduy. Bogor: Manuskrip.

Saleh Danasasmita dkk.

1987. Sawaka Darma, Sang Hyang Siksa Kandang Karesian, Amanat Galunggung. Bandung: Sundanologi.
Ngakan Putu Saputra (edt.).

2010. Upanisad Himalaya Jiwa, Intisari Upanisad. Media Hindu.

Jakob Sumardjo.

2013. Simbol-Simbol Mitos Pantun Sunda. Bandung: Kelir.

Louis O. Kattsoff.

1992. Pengantar Filsafat. Yogya: Tiara Wacana. .

C. G. Jung.

2003. Memories Dreams Reflections. Yogya: Jendela.

Frederick Sontag.

2002. Pengantar Metafisika. Yogya: Pustaka Pelajar.

Susilo Kusdiwanggo.

2015.Pancer Pangawinan Sebagai Konsep Spesial Masyarakat Adat Budaya Padi Kasepuhan Ciptagelar. Bandung : Disertasi Arsitektur ITB. 